\title{
Advance Propagation Techniques in Important Spice Crops
}

\author{
A. Thapa, S. Datta*, A.N. Dey and P. Baisare \\ Faculty of Horticulture, Uttar Banga Krishi Viswavidyalaya, Pundibari, Cooch Behar, \\ West Bengal -736165, India \\ *Corresponding author
}

\begin{abstract}
A B S T R A C T
India is the land of Spices, the largest producer, consumer and exporter of the spices in the world. According to the Spice Board of India, sixty three spices are grown in the country. More than $90 \%$ of spices produced in India are used for domestic consumption and the remaining are exported in raw and value added forms. A spice is a seed, fruit, root, bark, or other plant substance primarily used for flavouring, colouring or preserving food. Spices are distinguished from herbs, which are the leaves, flowers, or stems from plants used for flavouring or as a garnish. Sometimes, spices may be ground into a powder for convenience. Many spices have antimicrobial properties. This may explain why spices are more commonly used in warmer climates, which have more infectious diseases, and why the use of spices is prominent in meat, which is particularly susceptible to spoiling. India produces spices on 3.08 million ha with and annual production of about 5.4 million tons valued at about Rs. 4500 crores, contributing nearly $20 \%$ of world's production, $30 \%$ of the trade in terms of quantity but only $10 \%$ in terms of value. India is the biggest exporter of spices and annually exporting about 3,908 tones of spices and spice products valued around Rs. 4,460 crores. (NHB Database)The major constraints of spice production includes- Low farm productivity and consequent high cost of production, Non-coverage of high yielding varieties in farmers' fields, Non-availability of quality planting materials of high yielding varieties, Crop loss due to sever diseases and pest incidences, Poor postharvest handlings, Inadequate extension networks and Price instability. More over the traditional method of propagation in spice crops is followed the advance techniques for rapid multiplication like split bamboo method, serpentine method, soil mound method, in black pepper propagation and propagation of turmeric and ginger using single bud rhizomes and rapid clonal propagation techniques in high value crops like small cardamom and in-vitro propagation of crops like vanilla and cinnamon can be adopt for better utilization of land and supply of quality planting material (QMP).Hence the major bottle neck of the spice production is due to unavailability of quality planting material. Keeping this constraints in mind the advance propagation techniques can be adopt to overcome this problem.
\end{abstract}

\section{Introduction}

India is the land of Spices, the largest producer, consumer and exporter of the spices in the World. According to the Spice Board of India, sixty three spices are grown in the country. After independence, the spices continued to be one of the major foreign exchange earning items which necessitated expansion of area under these crops and hike 
in production because of its high enrich flavours and colouring agents for food. More than $90 \%$ of spices produced in India are used for domestic consumption and the remaining are exported in raw and value added forms. India's glory in the past as 'land of spices' attracted foreign buyers like French, Greek, British, Egyptians, Arabians, Portuguese, Chinese, Japanese and Dutch. They all had their mind set on Indian spices and vied each other to exploit them maximum to selfadvantage. India spices had contributed substantially in foreign exchange earnings.

A spice is a seed, fruit, root, bark, or other plant substance primarily used for flavoring, coloring or preserving food. Spices are distinguished from herbs, which are the leaves, flowers, or stems from plants used for flavoring or as a garnish. Sometimes, spices may be ground into a powder for convenience. Many spices have antimicrobial properties. This may explain why spices are more commonly used in warmer climates, which have more infectious diseases, and why the use of spices is prominent in meat, which is particularly susceptible to spoiling (Thomos et al., 2012). Spices are sometimes used in medicine, religious rituals, cosmetics or perfume production, or as a vegetable. Because they tend to have strong flavours and are used in small quantities, spices tend to add few calories to food, even though many spices, especially those made from seeds, contain high portions of fat, protein, and carbohydrate by weight. Many spices, however, can contribute significant portions of micronutrients to the diet. For example, a teaspoon of paprika contains about 1133 IU of Vitamin A, which is over $20 \%$ of the recommended daily allowance specified by the US FDA (USDA National Nutrient Database.2012). When used in larger quantity, spices can also contribute a substantial amount of minerals, including iron, magnesium, calcium, and many others, to the diet. Most herbs and spices have substantial antioxidant activity, owing primarily to phenolic compounds, especially flavonoids, which influence nutrition through many pathways, including affecting the absorption of other nutrients. One study found cumin and fresh ginger to be highest in antioxidant activity (Ninfali et al., 2007).

India produces spices on 3.08 million ha with and annual production of about 5.4 millionstonnes valued at about Rs.4500 crores, contributing nearly $20 \%$ of world's production, $30 \%$ of the trade in terms of quantity but only $10 \%$ in terms of value. India is the biggest exporter of spices and annually exporting about 4, 45,000tons of spices and spice products valued around Rs.4, 460 crores (contributing to about $12 \%$ of export earnings from agriculture or $1 \%$ of total national export earnings). The export of spices and spices products is growing up every year. But it is alarming that per capita land resources are decreasing day by day due to huge population pressure and industrialization. It is almost impossible to have a horizontal expansion of spice growing area. On the other hand casual natural hazards, pest and diseases outbreak, market fluctuation, etc. are also serious threats for getting that targeted outputs at a point of time. But sometimes, they concerned with some problems like non-availability of quality and high yielding varieties, low productivity mainly due to infestation of several diseases and pests, poor post-harvest handling practices, result in more production cost. Even, price insecurity and inadequate extension works are also major constraints against these rapid multiplication techniques. Hence, rapid multiplication of planting materials through modern propagation techniques is urgently needed.

\section{Propagation}

Plant propagation is the process or a way for multiplication or generation of new plantlets. Spices like coriander, cardamom, fenugreek, 
cumin, clove, nutmeg, allspice are propagated by seeds and some are propagated by vegetative ways i.e. by means of vegetative parts of the plant. For example, Black pepper (cutting), cardamom (suckers), tamarind (whip cum inarching, patch budding), cinnamon (cutting and layering), ginger, turmeric (rhizome), garlic (clove), vanilla (stem cutting).

\section{Conventional V/S modern propagation techniques}

Conventional propagation needs a large quantity of planting material which results less sprouting ratio, more incidences of disease and pests and poor root development as well as field establishment. Modern propagation techniques are more advantageous over conventional one. Through modern propagation techniques production of virus free, disease and insect pest resistant planting material with large quantities within a shorter space of time can be possible. These plants grow faster and more vigorously. Also gives higher yield as compare to conventional methods.

\section{Black pepper}

Black pepper can be propagated by seeds, cuttings, layering, and grafting. Seed propagation often results in genetic variation while other methods of propagation are slow and time consuming. So, there is a need to introduce efficient methods for rapid propagation of black pepper. In different countries of worlds like India, Sri Lanka black pepper is plants are multiplied rapidly in order to get more seedling in short duration and for quality planting material.

\section{Split bamboo methods}

A trench is made of $45 \mathrm{~cm}$ depth, $30 \mathrm{~cm}$ width and convenient length, filled with rooting medium comprising of forest soil, sand and farm yard manure in 1:1:1 ratio. Split halves of bamboo is fixed at 45 degree angle on a strong support. Rooted cuttings are planted in the trench at the rate of one cutting for each bamboo split. The lower portions of the bamboo splits are filled with rooting medium (preferably weathered coir dust-farm yard manure mixture in 1:1 ratio) and the growing vine is tied to the bamboo split in such a way so as to keep the nodes pressed to the rooting medium. As the cuttings grow, the bamboo splits are filled with rooting medium and each node is pressed down to the rooting medium and tied. When the vine reaches the top (3-4 months after planting of the cutting) the terminal bud is nipped off and the vine is crushed at about three nodes above the base, in order to activate the axillary buds. After about 10 days, the vine is cut at the crushed point and removed from the rooting medium and cut between each node. Each cutting with the bunch of roots intact is planted in polythene bags filled with fumigated potting mixture.

The advantages of this method of propagation are rapid multiplication (1:40), well developed root system, higher field establishment and vigorous growth as a result of better root system.

\section{Serpentine method}

It is one of the cheapest propagation techniques for production of rooted cuttings of black pepper is serpentine layering. In a nursery shed with roofing sheet or shade net, rooted black pepper cuttings are planted in polythene bags containing about $500 \mathrm{~g}$ potting mixture, which will serve as mother plants. As the plant grows and produces few nodes small polythene bags $(20 \times 10 \mathrm{~cm})$ filled with potting mixture may be kept under each node. The node may be kept gently pressed in to the mixture assuring contact with the potting 
mixture. Roots start growing from the nodes and the cuttings keep on growing further. Each node with the polythene bag is cut just below the rooted node. The rooted nodes will produce new sprouts in a week time and will be ready for field planting in two-three months' time. On an average, 60 cuttings can be harvested per mother plant in a year by this method.

\section{Soil mound method}

A soil mound of $2.5 \mathrm{~m} \mathrm{x} 0.60 \mathrm{~m}\left(45^{\circ}\right.$ angle $)$ of $2 \mathrm{~m}$ length (height) was prepared using locally available soil. In the upper layer of 5 $\mathrm{cm}$ of soil mound, well decomposed cow dung was mixed @ $1 \mathrm{~kg} / \mathrm{m}^{2}$. Rooted cuttings were planted at the base of soil mound in previously made trance at $20 \mathrm{~cm}$ spacing.

Bhuyan et al., (2015) concluded that soil mound method of black pepper multiplication showed superior result over conventional method of multiplication and followed by split bamboo method and serpentine method of propagation respectively. The longest vine length, more number of node and branches per vine and number of roots per node also highest in soil mould method. Similarly, the number of cuttings available per harvest, number of cuttings per year and maximum success percentage of cutting was greatest in soil mound method followed by split bamboo and serpentine method.

\section{Turmeric}

\section{Single bud rhizomes method}

Planting of turmeric by traditional way required more amount of quality planting material but less availability and highest cost are the main constraint. Even though, it takes nearly five to six months for rhizome development along with better crop establishment. Hence, to overcome these constraints rapid multiplication of turmeric through single bud method is one of the best methods. For this, a disease free, one to one and half month old seed rhizomes, treated with carbendazim @ 2g/litre and monocrotophos are used. These rhizomes are cut into small pieces having single bud, cured on palm mat, covered with $0.5 \%$ humic acid treated coco peat and sprinkled the water upto4 days. These sprouted single bud rhizomes sown in portray contains coco peat (100g) and Pseudomonas fluorescens (5g) and covered with polythene sheet. Finally after emergence of leaf, spray the crop with $0.5 \%$ humic acid and plantlets are ready for transplanting within 25-30 days.

Malhotra et al., (2016) reported that single bud techniques of turmeric for seedlings production in portrays was more beneficial as compared to direct planting method as showed on (Table 1).

\section{Micro propagation of turmeric}

Nasirujjaman et al., (2005) reported that an ideal micro propagation method of turmeric has been developed using rhizomes bud explants. Woody plant medium supplemented with different concentrations of BAP alone or in combination with different concentration of NAA produced varying degrees of multiple shoots. A Supplementations of $4.0 \mathrm{mg} /$ litre $\mathrm{BAP}+1.0 \mathrm{mg} /$ litre NAA gave the best result. In this case $95 \%$ of the inoculated explants induced multiple shoots within 8-10 days inoculation and the average number of shoots pre plant was 6.70. Rooting was spontaneous in almost all the treatment. Most of the regeneration shoots were successfully transferred to soil under field conditions.

Cheethaparambil et al., (2014) developed an efficient protocol for the development of microrhizome and minirhizome technology in high yielding variety of turmeric, Alleppey Supreme, using two media combinations and four types of culture vessels. 
Table.1 Comparison of direct planting and transplanting (single bud rhizome) method of turmeric on sprouting and vegetative phases of the plant

\begin{tabular}{|l|l|l|}
\hline Growing Phase & $\begin{array}{l}\text { Direct Planting } \\
\text { method (whole seed) }\end{array}$ & $\begin{array}{l}\text { Transplanting Method (single bud } \\
\text { rhizome) }\end{array}$ \\
\hline 1. Sprouting phase. & 20DAP & Plants have 34 leaves (1 month old). \\
\hline 2. Vegetative phase. & & \\
\hline i. One month after planting. & 2-3 leaves/plants & 6-7 leaves per plants. \\
\hline ii. Tillering stage. & 3 MAP & 1 1/2-2 MAP \\
\hline $\begin{array}{l}\text { 3. Rhizome development } \\
\text { phase. }\end{array}$ & Starts from 5 MAP & Starts from 3 MAP \\
\hline $\begin{array}{l}\text { 4. Rhizome maturation } \\
\text { phase. }\end{array}$ & 7-9 MAP & 6-7 MAP \\
\hline
\end{tabular}

It was observed that the variety showed highest response in liquid MS medium with $80 \mathrm{mg} /$ litre sucrose in Planton culture vessels. Microrhizome and minirhizome technologies were developed and comparative anatomical and histochemical studies were carried out. The microrhizome technology developed during the present study can be used for large scale production of planting materials in turmeric within a short period of time without compromising the quality and quantity.

\section{Ginger}

A transplanting technique in ginger by using single bud sprouts (about $5 \mathrm{~g}$ ) has been standardized to produce good quality planting material with reduced cost. The yield of ginger is at par with conventional planting system. The technique involves raising transplants from single sprout seed rhizomes in the pro-tray and planting in the field after 30-40 days. The advantages of this technology are production of healthy planting materials and reduction in seed rhizome quantity and eventually reduced cost on seeds.

\section{Micropropagation of ginger}

Zuraida et al., (2016) reported that ginger is cultivated for its medicinal value despite the constraints of longer life cycle. They developed the protocol for micro propagation of ginger by using buds generated on the surface of the ginger. Surface sterilized young buds of 0.5 $1.0 \mathrm{~cm}$ and $2-4 \mathrm{~cm}$ cultured on Murashige and Skoog (MS) supplemented with BAP showed the highest survival rate (55-65\%) and produced the highest average number of micro shoots per explants (3.2 \pm 0.06$)$ respectively. MS medium supplemented with different concentrations and combinations of auxin and cytokinin were used to evaluate shoot multiplication and root induction. BAP concentrations between 3.0-5.0 $\mathrm{mg} /$ litre was very effective in promoting micro shoots and resulted in 100\% of micro shoot propagation. Micro shoots cultured on MS medium supplemented with $3 \mathrm{mg} / \mathrm{litre}$ BAP and $0.5 \mathrm{mg} /$ litre NAA produced the highest number of shoots while $0-0.5 \mathrm{mg} /$ litre BAP enhanced shoot length and $3 \mathrm{mg} /$ litre NAA in combination with BAP produced highest number of roots Micro shoots maintained on MS medium supplemented with $4.5 \%$ sucrose produced the highest number of plantlets $(23 \pm 2.5)$ and roots per explants (15.4 \pm 2.4$)$ meanwhile reducing the length of lateral roots $(2.6 \pm 0.2)$.

Abbas et al., (2011) also developed the promising protocol for in vitro propagation of Zingiber officinale Rosco using sprouting buds was established. Sprouting buds were sterilized and cultured onto MS medium supplemented with different growth regulators. Augmentation of MS-medium with $4.5 \mathrm{mg}$ / litre BAP recorded 
the highest percentage of shootlets multiplication. Shootlets were highly rooted on half strength of B5 medium supplemented with $1.0 \mathrm{mg} /$ litre NAA. The maximum percentage of acclimatization, hardening and rhizomes production of in vitro derived plants in greenhouse was $80-100 \%$.

\section{Rapid multiplication techniques of small cardamom}

Small cardamom is propagated by rapid clonal propagation method. One grown up sucker and a young growing shoot are planted at $1.8 \times 0.6$ $\mathrm{m}$ spacing, which is protected with erecting pandal. From one planting unit about 32-42 suckers produced after 12 months. Hence in one hectare of clone nursery about 1, 48,144-1, 94,439 plants were produced in 12 months through rapid clonal multiplication techniques (Ankegowda and Biju, 2012).

\section{Micropropagation of large cardamom}

Pradhan et al., (2014) Investigation was achieved with an efficient, simple micropropagation methods was standardized for Ammomum subalatum cv. Ramsey for the production of disease free and rapid multiplication of planting material of Large cardomom micro-propagules and conservation of genetic resources of large cultivator variety of Sikkim.

Modified MS medium with $4 \%$ of sucrose with different concentration of hormone showed the suitable medium for multiplication of large cardamom. A total of 52 different hormone concentrations of growth hormone/ cultured medium were examined. The maximum number of shoots and roots were observed on (MS+ sucrose $40 \mathrm{~g}+\mathrm{BAP} 3 \mathrm{mg} / \mathrm{litre}+0.5 \mathrm{NAA}+2$ $\mathrm{mg} / \mathrm{litre}$ ) and second was (MS+ 40g sucrose + BAP $3.5 \mathrm{mg} /$ litre + $0.5 \mathrm{NAA}+2 \mathrm{mg} / \mathrm{litre})$. After individually subcultured on same fresh medium, adventitious buds were initiated after 10-15 days of culture, complete plantlets developed within 50 days and maintained for 18 months without decreasing the multiplication rate. The combination of cytokinins and auxins in the culture medium enhanced the response in a number of plants in terms of shoot and root growths, with $100 \%$ in-vitro multiplied plantlets were successfully transferred into field.

\section{In-Vitro propagation of vanilla}

In-vitro propagation of vanilla plants showed profuse shooting with the supplement of MS +BAP@1.5 mg/litre media and along with that better rooting was noticed with the application of $0.5 \mathrm{mg} /$ litre of IBA. For hardening of plantlets soil + coco pith @ (1:1) found better for survival of plantlets (100\%) (Neelamavar 2005)

\section{In-Vitro propagation of cinnamon}

Subasinghe et al., (2016) reported that 15\% Clorox for $20 \mathrm{~min}$ was very effective in minimizing pathogenic contaminants embryos as well as minimum browning. $1 \mathrm{~g}$ activated charcoal was effective for establishment of invitro culture, recording minimum browning effect, enhancing stem elongation and leaf initiation. Treatment combination of $0.1 \mathrm{mg}$ $\mathrm{NAA}+4.0 \mathrm{mg} \mathrm{BAP}+1.0 \mathrm{~g}$ activated charcoal in full strength MS medium was effective for adventitious root elongation on in-vitro microstem cuttings and given the highest root length after 6 weeks of incubation period. Coir dust was the best potting medium for acclimatization giving maximum survival $(90 \%)$.

More over the traditional method of propagation in spice crops is followed the advance techniques for rapid multiplication like split bamboo method, serpentine method, soil mound method, trench method in black pepper propagation and propagation of turmeric and ginger using single bud rhizomes and rapid clonal propagation techniques in high value crops like small cardamom and in-vitro propagation of crops like vanilla and cinnamon can be adopt for better utilization of land and supply of quality planting material (QMP).

Hence the major bottle neck of the spice production is due to unavailability of quality 
planting material. Keeping this constraints in mind the advance propagation techniques can be adopt to overcome this problem.

\section{References}

Abbas, M.S., Taha H.S, Aly U.I, Shabrawi H.M and Gaber S.I. 2011. In vitro propagation pf Ginger (Zingiber officinals Rosco). Journal of Genetic Engineering and Biotechnology 9(2): 165-172

Ankegowda, S.J., and Biju C.N. 2012.Propagation Techniques in Small cardamom. Spice facets. December 11, 2012.

Bhuyan, M.H.M.B., Rahman S.M.L and Sarker J.C. 2015. Explicating proper multiplication method for black pepper propagation in Bangladesh. Advance in Agriculture and Biology 4(2):75-78.

Cheethaparambil, A., Pillai G.S. and Balachandran, I. 2014. In vitro microrhizome and minirhizome production in turmeric (Curcuma longa L.) cultivar Alleppey Supreme and its comparative anatomical and histochemical analysis. International Journal of Current Microbiology and Applied Sciences 3(3): 535-542

Malhotra, S.K., Cherian $\mathrm{H}$ and R.Chitra, Balakrishnan S. 2016. Single bud rhizomes techniques of turmeric for seedlings production in portrays. Indian Journals of Arecanut, spice and medicinal plants 18(3):34-36.

Nasirujjaman, K., Uddin M.S, Zaman S, Reza M.A. 2005. Micro propagation of Turmeric (Curcuma longa L.) through in vitro Rhizome Bud Culture. Journal of Biology Sciences 5(4):490-492.

Neelannavar, V.S., 2005. M.Sc thesis University of Agriculture Science Dharwad.
Ninfali, Paolino, Mea, Gloria; Giorgini, Samantha; Rocchi, Marco; Bacchiocca, Mara (2007)."Antioxidant capacity of vegetables, spices and dressings relevant to nutrition". British Journal of Nutrition93 (02): 257-66.

Pradhan, S., Pradhan S, Basistha B.C. and Subba K.B. 2014. In vitro micropropagation of Amomum subulatum (Zingiberaceae), a major traditional cash crop of Sikkim Himalaya. International Journal of Life Sciences Biotechnology and Pharma Researches 3(2): 2250-3137.

Prasath, D., K. Kandiannan, V. Srinivasan, M. Anandara.2016. Improved Propagation Techniques in Ginger and Black Pepper. Spice India 29(1): 27-29.

Subasinghe, S., Hettiarachchi C.S. and Iddagoda N. 2016. In-vitro propagation of cinnamon (Cinnamomum verum Presl) using embryos and in vitro axillary bud. Journal of Advance Agricultural Technologies 3(3):164-169.

The Hindu. June 22, 2006. Propagating black pepper through Serpentine method.http://www.thehindu.com/todayspaper/tp-features/tp-sci-tech.

Thomas, Frédéric, Daoust, Simon P., Raymond, M. (2012). "Can we understand modern humans without considering pathogens?" Evolutionary Applications.5 (4): 368379.

USDA National Nutrient Database: Nutrient data for 02028, Spices, paprika, Retrieved August 26, 2012.

Zuraida, A.R., Mohd Shukri M.A, Erny S. M.N, Ayu N, Che Radziah C. Z, Pavallekoodi, $\mathrm{G}$ and Sreeramanan, S. 2016. Micropropagation of ginger (Zingiber officinale var. Rubrum) using buds from microshoots. Pakistan journal of Botany 48(3):1153-1158.

\section{How to cite this article:}

Thapa, A., S. Datta, A.N. Dey and Baisare, P. 2017. Advance Propagation Techniques in Important Spice Crops. Int.J.Curr.Microbiol.App.Sci. 6(9): 1979-1985.

doi: https://doi.org/10.20546/ijcmas.2017.609.242 